III. Aus der chirurgischen Klinik des Herrn Geh. Med.-Rath Prof. Dr. Fischer in Breslau.

\section{Ein Fall von Akromegalie.}

\section{Von Dr. Max Litthauer.}

Eude September vorigen Jabres stellte sich in der Chirurgischen Klinik zu Breslau ein Mann zur Behandlung, der an einer leichten Periostitis des Unterkiefers litt, aber mebr durch die eigenthümliche Bildung seines Gesichts interessirte.

Bei genauerer Untersuchung fanden sich ausser dieser merkwürdigen Formation des Gesichts noch andere Symptome, welche in ibrer Gesammtheit lehrten. dass der Patient an der von Pierre Marie ${ }^{1}$ ) zuerst sogenannten Akromegalie litt.

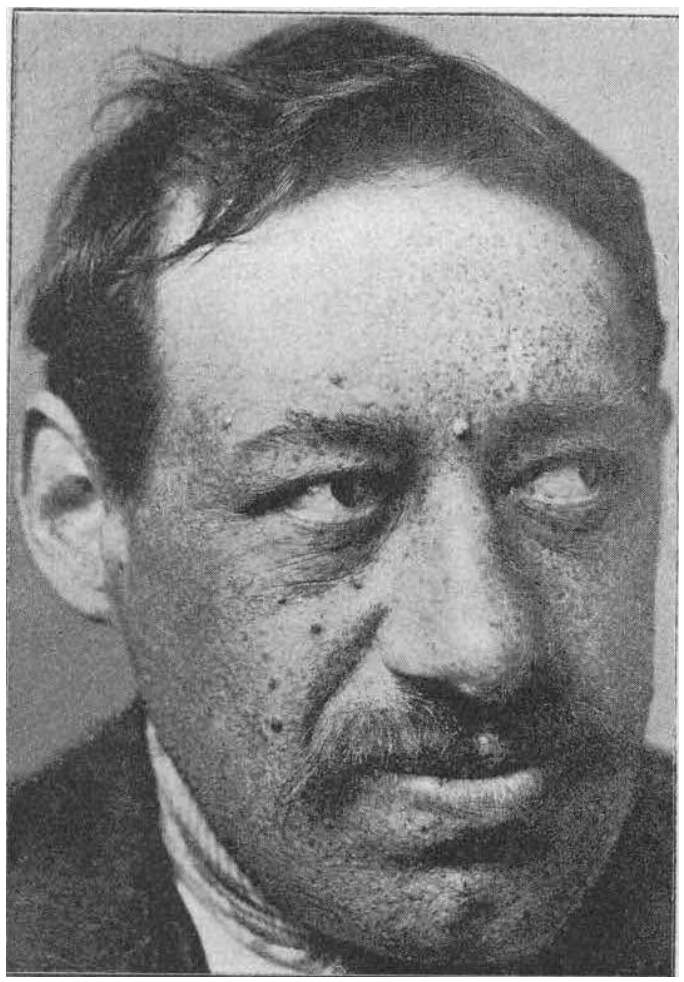

Bei der grossen Seltenheit dieser Erkrankung scheiut es mir berechtigt, noch jeden einzelnen Fall zu veröffentlichen. Ich gebe daher im nachstehenden eine genaue Beschreibung des von uns beobachteten Falles.

Auamnese: Patient ist der Müllergeselle W. L. aus Breslau. Er stammt aus gesunder Familie und will nie erheblich krank gewesen sein. Seit seinem 12. Lebensjahre ist er in seinem Gewerbe thätig; in den Jahren 1874-77 genügte er seiner Militärpflicht.

Patient ist verheirathet und hat aus seiner Ehe drei Kinder gehabt, von denen zwei im jugendlichen Alter gestorben sind.

Den Beginn seines Leidens verlegt er in das Jahr 1878, also in das auf seine Entlassung vom Militär folgende Jabr. Damals fingen Hände und Gesicht an, grösser zu werden. Die Vergrösserung hat bis vor zwei Jahren langsam, aber stetig zugenommen; seitdem ist ein Stillstand im Wachsthum eingetreten.

In den ersten Jahren hat die Verorösserung der Hände dem Patienten keine Beschwerden verursacht, in den letzten Jahren dagegen sollen ihn die Hände öfters eingeschlafen. und er dadurch in seiner schweren Arbeit behindert gewesen sein

Die geschlechtlichen Functionen werden in normaler Weise ausgeübt die Libido sexualis ist weder abnorm früh aufgetreten, noch hat sie bis jetzt wahrnehmbar abgenommen.

Syphilitische Infection wird geleugnet.

Status: Patient ist ein kleiner untersetzter, kräftig gebauter Mann mit etwas schlaffer Muskulatur und sehr geringem Panniculus adiposus.

1) Pierre Marie, Sur deux cas d'acromégalie, hypertrophie singulière non congénitale des extrémités supérieures, inferieures et céphaliques.
Haut und sichtbare Schleimhäute sind auffallend blass, erstere hat eine in's gelbliche spielende Farbe. Keine Oedeme oder Exantheme, das Sensorium ist frei, doch ist das Denkvermögen etwas träge, die Sprache schleppend. Die Körperhaltung des Patienten ist eine leicht gebeugte.

Pupillen beiderseits gleich weit, auf Lichteinfall prompt reagirend. Der Kopf zeigt ein starkes Missverhältniss zwischen Schädel und Gesicht; letzteres an Grösse gegen den ersteren stark prävalirend. Die Form des Gesichtes ist eine längsovale, welche namentlich durch die starke Vergrösserung des Unterkiefers bedingt wird. Der horizontale Ast desselben, vom Kieferwinke bis zum Kinn gemessen, misst $13 \frac{1}{2} \mathrm{cr}$, der aufsteigende $9^{1 / 4} \mathrm{~cm}$. Er überragt den Oberkiefer etwa um $1 \mathrm{~cm}$, sodass man zwischen beide Zahnreihen bequem die Kuppe des kleinen Fingers einlegen kann.

Die Nase ist sehr gross und dick, Länge $7 \mathrm{~cm}$, Breite von einer Nasoabialfalte zur anderen $8 \mathrm{~cm}$

Die Unterlippe, stark herabhängend, zeigt eine leichte Cyanose; sie misst an der breitesten Stelle $2 \% \mathrm{~cm}$.

Die Haut am ganzen Gesicht etwas verdickt. Die übrigen Gesichtsknochen vollkommen normal.

Der Hals ist kurz, Umfang $41 \mathrm{~cm}$; auffallende Veränderungen an ${ }^{-}$der Thyreoidea, die nicht durchzufühlen ist, sind nicht zu bemerken.

Der Thorax ist stark gewölbt; der Umfang desselben beträgt 106 bis $102 \mathrm{~cm}$. Die Rippen sind sehr breit, die Wirbelsäule in den obersten Partieen des Brusttheils und den untersten 'des Halstheiles kyphotisch ausgebogen. In der Fossa supraspinata dextra ein $10 \mathrm{~cm}$ langes und breites Liporm.

Die physikalische Untersuchung von Herz und Lunge ergiebt durchaus normale Verhältnisse; besonders ist hervorzuheben, dass eine becherförmige Dämpfung im oberen (Theil des Sternums, wie sie Erb') und Friedreich' beobachtet haben, nicht zu constatiren ist.

Von Seiten der Abdominalorgane sind pathologische Veränderungen nicht zu constatiren; ebenso wenig zeigeu die Functionen des Urogenifalapparates eine Abweichung von der Norm.

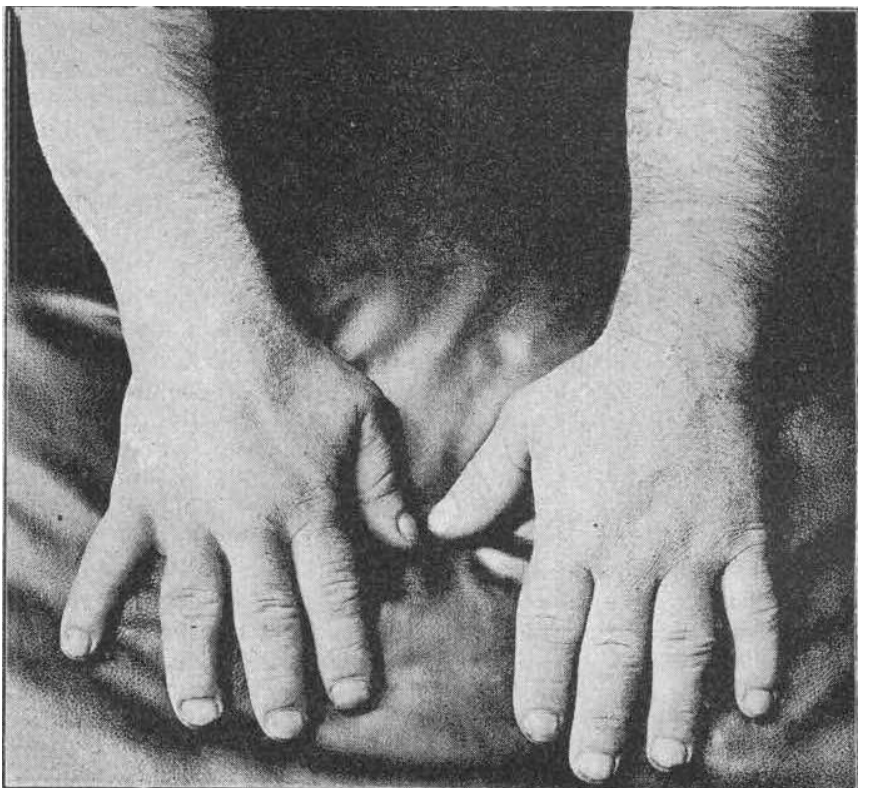

Das Blut reigt bei der mikroskonischen Untersuchung das normale Verhältniss zwischen weissen und rothen Blutkörperchen, dagegen ist der Ilaemoglobingehalt, gemessen mittels Fleischl's Ilaemometer, auf $40 \%$ des normalen herabgesetzt.

Die oberen Extremitäten beiderseits, abgesehen von den Händen, durchaus normal, die Bewegungen gehen in allen Gelenken frei und ohne wahrnehmbare Gerāusche vor sich. Man fühlt weder an den Gelenken noch an den Knochen Hervorragungen oder Vorsprünge. Von dem normal entwickelten Vorderarm contrastiren auf's schärfste die colossalen Hände. Dieselben sind sowohl in der Längsrichtung als auch in die Breite vergrössert, doch überwiegt die Breitenausdehnung, und es resultirt daraus der "tatzenartige" Charakter der Hände, den alle Autoren gleichmässig als charakteristisch für Akromegalie hervorheben.

Die Farbe der Hände ist leicht bläulich, die Hände fühlen sich etwas kühl an; die Haut derselben ist verdickt, ebenso das subcutane Gewebe. Den wesentlichsten Antheil an der Vergrösserung haben jedoch die Knochen.

Die Bewegungen der Hände werden normal ausgeführt; die Gelenke sind frei.

An den Nägeln keine auffallenden Veränderungen.

Die an der rechten Hand auf linken fast genau übereinstimmen, sind folgende: $20 \mathrm{~cm}$.

Länge der Hand von der Handwurzel bis zur Spitze des Mittelfingers

$$
\begin{aligned}
& \text { Länge des Daumens . . . . . . } 7 \mathrm{~cm}
\end{aligned}
$$

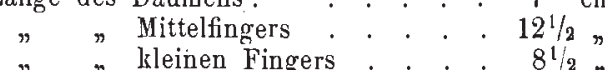

1) Erb, Ueber Akromegolie. Dtschs. Arch. f. klin Medicin Bd. 42. Bd. 43 


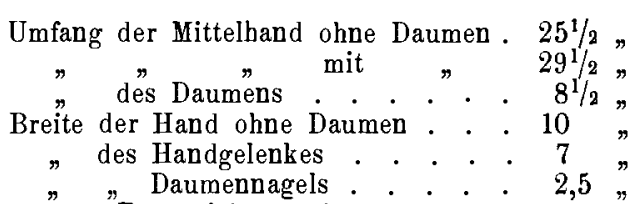

An den unteren "Extremitäten zeigen Ober- und Unterschenkel die gewöhnlichen Grössenverhältnisse, dagegen sind die Füsse auffallend gross und breit, sie sollen sich jedoch seit dem Abschluss des Wachsthums nicht vergrōssert haben. Der linke zeigt leichte Valgusstellung. Die Länge des rechten Fusses $29 \mathrm{~cm}$, Länge der grossen Zehe $8 \mathrm{~cm}$, Umfang über den Malleolen $28 \mathrm{~cm}$. Die Maasse des linken Fusses sind denen des rechten ganz gleich.

Die Untersuchung der Augen, die Herr Dr. Landtmann in Breslau so freundlich war, voczunehmen, ergiebt folgenden Befund. Bulbi sehr gross, associirt, gut beweglicb, alternirender Strabismus divergens bei beiderseitiger Insufficienz der Recti interni.

Sehvermögen beiderseits fast 1/2. Starke Myopie auf beiden Augen, rechts - $1 / 7$, links - $1 / 4 ;$ Gesichtsfeld rechts ca. $10^{\circ}$, links etw'd $15^{0}$, concentrisch eingeengt.

Ophthalmoskopisch sind die Medien klar; am Hintergrund starke Rare. fication des Pigmentblattes, ferner rechts eine verschwommene kleinere, links eine ebensolcbe grössere Sclerectasie.

Die Sensibilität am Rumpf und an den Extremitäten in allen Qualităten normal; die elektrische Untersuchung ergiebt nicht erheblich von der Norm abweichende Verhältnisse.

Nach dem vorstehenden Befunde bedarf die Diagnose Akromegalie keiner weiteren Begründung.

Die nach der Pubertät auftretende Vergrösserung des Unterkiefers, der Nase, der Unterlippe und der Hände charakterisiren den Fall zur Genüge als hierher gehörig. Wer sich die Mühe nehmen will, die beigegebenen Photographieen mit der Abbildung von Pierre Marie's zweitem Falle zu vergleichen, wird die Aehnlichkeit der beiden Gesichter ohne weiteres erkennen.

Leider ist die Aetiologie unseres Falles eben so dunkel, wie die aller bisher beobachteten Fälle. Es ist uns auch nicht gelungen, irgend eines der Momente, welche von anderen Autoren als ätiologisch bemerkenswerth angeführt werdell, in unserem Falle zu constatiren.

Es ist schon erwähnt, dass die becherförmige Dämpfung im oberen Theil des Sternums, die in den Fällen von Erb und Friedreich so auffallend ist, sich bei unserem Falle nicht findet. Auch sonst sind keine Zeichen für die Persistenz der Thymusdrüse vorhanden. Ebensowenig sind Anomalieen an der Schilddrüse zu constatiren, und schliesslich fehlen auch alle Symptome, die auf einen Tumor der Hypophysis schliessen lassen könnten.

W. A. Freund ${ }^{1}$ ) hat in seiner bekannten Monographie die Akromegalie mit der Pubertät und mit den geschlechtlichen Functionen in Zusammenhang gebracht, namentlich gestützt auf das mehrfach beobachtete frühzeitige Eintreten der Menopause, auf das sehr frühe Auftreten und Verschwinden des Geschlechtstriebes. Freund wird namentlich von Verstraeten ${ }^{2}$ ) in seiner Anschauung unterstützt, während $\mathrm{Vir} \mathrm{chow}^{3}$ ) dieselbe bekämpft. Im vorliegenden Falle sind Anomalieen der sexuellen Functionen nicht vorhanden gewesen, er ist also jedenfalls nicht geeignet, die Freund'sche Hypothese zu stïtzen.

Eine anatomische Ursache zur Erklärung der Akromegalie ist bisher, abgesehen von der durch $\mathrm{Klebs}^{4}$ ) in seinem Falle gefundeuen allgemeinen Erweiterung der Arterien und Capillaren, nur in dem Falle von Holschewnik off ${ }^{5}$ ) und v. Recklinghausen ${ }^{6}$ ) beschrieben worden, welche in ihrem zur Section gekommenen Falle Syringomyelie und hyaline Degeneration zahlreicher peripherischer Nerven an den oberen und unteren Extremitäten fanden.

Auch nach dieser Richtung ist der Befund in unserem Falle durchaus negativ.

Kurz hervorheben möchte ich noch die von uns beobachtete Anämie und starke Herabsetzung des Hämoglobingehalts des Blutes; in welchem Zusammenhange dieses Symptom mit der Akromegalie steht, lasse ich dahingestellt.

Zum Schluss ist es mir eine angenehme Pflicht, meinem früheren Chef, Herrn Geheimrath Prof. Dr. Fischer für die Ueberlassung des Falles meinen verbindlichsten Dank zu sagen.

1) W. A. Freund, Ueber Akromegalie. Volkmann's Sammlung klin. Vortr. No. 329 u. 330.

2) Verstraeten, L'acromégalie IX, 5 u. 6 1889; referirt Schmidt's Jabrbücber 1889 p. 137.

3) Vircbow, Ueber Akromegalie. Berl. klin. Wocbenschr. 1889 No. 5.

4 Klebs und Fritsche, Ein Beitrag zur Pathologie des Riesenwucbses. Leipzig, Vogel 1884.

5) Holschewnikoff, Ein Fall von Syringomyelie etc. Virchow's Archiv Bd. 119.

6) v. Recklinghausen, Ueber Akromegalie. Virchow's Archiv Bd. 119. 